\title{
A Review Paper of Hepatitis C virus (HCV) Include Risk Factors, Diagnostic Tests, Early Treatment Options, and Treatment of HCV by Sofosbuvir and Ribavirin
}

\begin{abstract}
Rehana $^{1} *$ \& Akhlaque Ahmed Lashari $^{2}$

${ }^{1,2}$ Institute of Molecular Biology and Biotechnology, Bahauddin Zakariya University, Multan, Pakistan.
\end{abstract}

\section{Corresponding Author}

Author Email:

rehanakhan5556@gmail.com

DOI: $10.38177 / A J B S R .2020 .2201$

\section{Abbreviations}

(HCV): Hepatitis C Virus, (HIV): human immunodeficiency virus, (RNA): Ribonucleic Acid, (IFN): interferon, (RBA): Ribavirin, (SVR): sofosbuvir.

\section{Introduction}

$\mathrm{HCV}$ is a small, enclosed, positive-sense, single, stranded RNA virus with a 9.6 genome [1]. chronic hepatitis $\mathrm{C}$ virus (HCV)infection is the main cause of liver cirrhosis and hepatocellular carcinoma (HCC) [2][3][4]. Hepatocellular carcinoma is common importance of HCV-related cirrhosis, with an annual rate of $1 \%-8 \%$ [5]. Chronic hepatitis C infections can cause liver injury, with the development of cirrhosis and hepatocellular carcinoma [6].in 2015, 71 million people universal were living with one of the six major genetic constitution hepatitis $\mathrm{C}$, virus (HCV) and 399000 people died from the infection [7][8]. In high-income countries (HIC), the occurrence of chronic hepatitis $C$ is generally below $2 \%[4]$.

The effective treatment selections are today existing universal, with the continuous virologic response over 90-95\% for new antiviral medication treatment 8-12 weeks. Earlier the profile of novel treatments, IFN plus RBV was normal of care. While the sustained virologic response was over $50 \%$ total, irrespective of genetic makeup, the contrasting effects of Interferon (IFN) related behavior were important. Flu-like conditions and even depression were not rare mid interferon (IFN) treated patients [9]-[11].

In the initial 1990s, a 6-month course of interferon alfa (IFN- alfa) monotherapy, the first known treatment for long-lasting $\mathrm{HCV}$, caused in conformed virologic response rates (SVR) 
of $6-12 \%$ [12], [13]. The flexibility of the therapy period to 12 months enhanced SVR to $16-20 \%$ [13]. The adding of ribavirin to IFN-alfa significantly improved SVR to $35-40 \%$. More recently, the pegylation of IFN-alfa, when used concurrently with ribavirin, has further enhanced SVR to 54-56\% [10], [12], [14], [15].

In vitro data have also not necessary that RBV has a preservative antiviral when mutual with protease inhibitors and synergistic effect in grouping with IFN and a protease inhibitor [16]. In 2013, sofosbuvir, alternative HCV-specific antiviral targeted to the NS5B polymerase, received nutrition and medicine management (FDA) approved. RBV also prevents the replication of other flaviviruses, such as bovine viral diarrhea virus, GB virus $B$, and poliovirus [12]. Between 2015 and 2030, the who objects contain decreasing new HCV infections by $80 \%$, and the volume of $<5 \%$ to $90 \%$ and the number of qualified persons getting HCV treatment from $<1$ provides simpler, shorter and more effective interferon limiting therapies for HCV geno\% to $80 \%$. Sofosbuvir types 1 to 6 [17].

Sofosbuvir is identified for the treatment of long-lasting HCV infection as a factor of a combination antiviral treatment routine[18], [19]. sofosbuvir mixture with ribavirin and /or peginterferon-alfa has exposed value in topics with HCV genotype 1, 2, 3, or 4, infection, containing those with hepatocellular carcinoma assembly Milan criteria and those with HCV/HIV-coinfection.

In careful case, patients infected with genotype $1 \mathrm{HCV}$ who are impotent to tolerate interferon or who are interferon ineligible can be treated with sofosbuvir plus ribavirin for 24 weeks Patients infected with HCV genotype 2 should treat sofosbuvir plus ribavirin for 12 weeks[17].

A patient ill with HCV genotype 3 must be treated with sofosbuvir plus ribavirin for 24 weeks. Person patients with hepatocellular carcinoma pending liver transplantation would be treated with sofosbuvir plus ribavirin for up to 48 weeks or till liver transplantation, which happens first[19]. An alternative study available in 2012 described the incidence of HCV in Egypt as around 7 per 1,000 person-years, corresponding to 500,000 HCV infections per year,[20] despite general automatic for infection control[4].

Whereas risky parenteral therapy for schistosomiasis from the 1920s to 1980s was the chief source of HCV infection in Egypt,[21]the unsafe medical procedures remain the major risk factor[22]. Pakistan has the sixth-largest people in the biosphere and a reasonable-to-high prevalence of $\mathrm{HCV}$. The assessed HCV occurrence is $5.4 \%,[23]$ in place of $9-10$ million persons with the infection. Iatrogenic $\mathrm{HCV}$ exposure is the main risk factor for $\mathrm{HCV}$ transmission in Pakistan[23]. 


\section{Risk Factors of HCV}

- History of injection drug use[24].

- Having conventional blood transfusion, blood products, or an organ transplant in Canada before 1992[25].

- A history of or recent incarceration.

- Having received chronic hemodialysis[26].

- HIV infection [27], [28].

- complete unsterilized needles or transfusion with contaminated blood,

- remains a major route of HCV infection

- particularly in low-income countries (LMICs).[21], [25], [29].

\section{Diagnostic Tests}

Analytic tests for HCV infection are separated into serological analyses for antibodies and molecular tests for the viral constituent part. The finding is founded on a significant transmit with the result of serum antibodies against HCV. Screening assess based on antibody detection and has importantly reduced the danger of transfusion-related infection. Antibodies contrary to HCV are still visible during and after treatment, of any kind the reply, and vital not be tested for again[30], [31]. Analysis based on molecular detection of HCV RNA has also been introduced. Qualitative HCV RNA tests are based on the PCR technique and have a lower limit of detection of fewer than 100 duplicates of office RNA per $\mathrm{mL}$ of serum (50 IU/mL). Testing for HCV RNA is a consistent way of screening HCV infection and is the maximum exact test of infection[30], [31]. Occult infection with HCV has been supposed in patients with irregular transaminases and negative HCV PCR in the serum, but positive HCV PCR in the liver, or positive in-situ hybridization, or positive obvious HCV RNA in bordering blood mononuclear cells[32].

\section{Early Treatment Options}

The initial pharmacological action for hepatitis C was introduced in the 1990s and involved of non-pegylated [33][34] Interferon-alpha-2a or alpha -2b monotherapy [27], [33], [35]. Treatment duration was 24 or 4 weeks, conditional on hepatitis-C genotype, and essential thrice-weekly doses[36]. In the latter half of the 1990s, Pegylated Interferon-alpha preparations were introduced. Pegylation displays down the rate of drug preoccupation, reductions delivery, and failures in the rate of removal [37]. Response rates for pegylated interferon were originated to be heavily in need of on patient-specific characteristic; body 
mass index, degree of pretreatment hepatic damage, IL-2B genotype, and hepatitis C RNA viral load[34], [38].

\section{Treatment of HCV by Sofosbuvir and Ribavirin}

Sofosbuvir, an oral nucleotide equivalent inhibitor of the HCV-specific NS5B polymerase, has freshly accepted for the action of chronic HCV infection [39]. The labeled for a patient with peginterferon alfa and ribavirin for 12 weeks. In Stage 2 LONESTAR experimental, patients with HCV genotype 1 infection lacking cirrhosis who conventional 8 or 12 weeks of ledipasvir-sofosbuvir, with or without ribavirin, had rates of sustained virologic response of 95 to $100 \%$ [19]. Stage 3 ION-1 and ION-2 trials presented that 12 weeks of treatment with ledipasvir-sofosbuvir was related to retort charges that were alike to those between patients who received 24 weeks of treatment.

Current evidence, however, suggests that the addition of thirds directing antiviral agents to ledipasvir-sofosbuvir may allow a father to give of the period of treatment to 6 weeks [40]. In phase 2 trials, sofosbuvir plus ribavirin was used to treat patients both before and after liver transplantation, including those with compensated cirrhosis, with moderate efficacy after prolonged (24-48 weeks) administration [41]-[43].

Ribavirin is nucleoside analog of molecular weight [12], [35]. Ribavirin alone had no effects on liver histology. when combined with standard or pegylated interferon, however, ribavirin enhanced virologic, biochemical, and histologic response rates compared with interferon alone [14], [44]-[46]. Further trial data show that the addition of ribavirin enhances SVR rates by about $25 \%$ to $30 \%$ and suggests a mechanism by which ribavirin enhances HCV-RNA decline and improves the long-term outcome [47].Sofosbuvir plus ribavirin for 12-24 week has been evaluated as a treatment for chronic genotype (G) 1-4 HCV infection, with variable efficacy ( high in G2 [SVR at 12 weeks, or SVR12, 88\%-97\% ],moderate in G1 [ SVR12 68\%-85\%] and G3 [SVR12 56\%-89\%[48], [49]. Additional side effects associated with ribavirin specifically include anemia, respiratory complications, and teratogenicity[27], [50].

\section{Conclusion}

Long-lasting hepatitis $\mathrm{C}$ is an important source of cirrhosis, hepatocellular carcinoma, digestive hemorrhage, and hepatic shortage. The present dynamic HCV therapeutic expansion environment has provided great optimism breakthroughs that have been attained in analysis and treatment. Antiviral actions decrease liver fibrosis development and can even reverse cirrhosis. Unfortunately, even in developed countries, death due to hepatitis $C$ is increasing due to inadequate detection and treatment. 


\section{Acknowledgements}

None.

\section{Funding information}

None.

\section{References}

[1] V. Conteduca, D. Sansonno, S. Russi, F. Pavone, and F. Dammacco, "Therapy of chronic hepatitis C virus infection in the era of direct-acting and host- targeting antiviral agents," J. Infect., 2013.

[2] M. Nakano, "Predictors of hepatocellular carcinoma recurrence associated with the use of direct acting antiviral agent therapy for hepatitis $C$ virus after curative treatment: A prospective multicenter cohort study," no. October 2018, pp. 1-8, 2019.

[3] C. Concepts and H. B. El-serag, "Hepatocellular Carcinoma," 2011.

[4] E. Gower, C. Estes, S. Blach, K. Razavi-shearer, and H. Razavi, "Global epidemiology and genotype distribution of the hepatitis C virus infection Journal of Hepatology Update : Hepatitis C," J. Hepatol., vol. 61, no. 1, pp. S45-S57.

[5] H. B. El-serag and F. Kanwal, "Epidemiology of Hepatocellular Carcinoma in the United States :," vol. 60, no. 5, pp. 1767-1775, 2015.

[6] C. W. Kim and K. Chang, "Hepatitis C virus : virology and life cycle," pp. 17-25, 2013.

[7] G. Norkrans and O. Karlstro, "Treatment of hepatitis C virus infection for adults and children: Updated Swedish consensus recommendations," vol. 48, no. 4, pp. 251-261, 2016.

[8] M. Bulterys and S. Sadiq, "Treatment of people diagnosed with chronic hepatitis C virus infection," p. 219295, 2018.

[9] B. A. Chis, C. Nicula, and D. Dumitrascu, "Early optic neuropathy during pegylated alfa 2-B interferon and ribavirin HCV treatment. A case report," vol. 92, no. 3, pp. 308-310, 2019.

[10] H. C. V Rna, "P EGINT E RF E RON ALFA - 2a PLUS RIBAV IRIN FOR H EPATITIS C PEGINTERFERON ALFA-2a PLUS RIBAVIRIN FOR CHRONIC HEPATITIS C VIRUS INFECTION," vol. 347, no. 13, pp. 975-982, 2002.

[11] L. A. Lucaciu and D. L. Dumitrascu, "Depression and suicide ideation in chronic hepatitis C patients untreated and treated with interferon : prevalence, prevention, and treatment," pp. 440447, 2015.

[12] V. Clark and D. R. Nelson, "chronic hepatitis C," vol. 32, no. 0 1, pp. 103-107, 2013.

[13] H. C. V Rna et al., "Diagnostic Tests for Hepatitis C," pp. 1-5. 
[14] M. P. Manns, J. G. Mchutchison, S. C. Gordon, V. K. Rustgi, M. Shiffman, and R. Reindollar, "Peginterferon alfa-2b plus ribavirin compared with interferon alfa-2b plus ribavirin for initial treatment of chronic hepatitis C: a randomised trial," vol. 358, pp. 958-965, 2001.

[15] A. A. Modi and T. J. Liang, "Hepatitis C: a clinical review," pp. 10-14, 2008.

[16] W. P. Hofmann, T. L. Chung, C. Osbahr, S. Susser, U. Karey, and U. Mihm, "Original article Impact of ribavirin on HCV replicon RNA decline during treatment with interferon- $a$ and the protease inhibitors boceprevir or telaprevir," vol. 704, pp. 695-704, 2011.

[17] A. Manuscript, "NIH Public Access," vol. 161, no. 8, pp. 546-553, 2015.

[18] M. Mizokami et al., "Ledipasvir and sofosbuvir fi xed-dose combination with and without ribavirin for 12 weeks in treatment-naive and previously treated Japanese patients with genotype 1 hepatitis C: an open-label , randomised , phase 3 trial," Lancet Infect. Dis., vol. 3099, no. 15, 2015.

[19] H. Liao, P. Tan, J. Huang, and K. Yuan, "Ledipasvir\&nbsp;+ Sofosbuvir for Liver Transplant Recipients With Recurrent Hepatitis C: A Systematic Review and Meta-analysis," Transplant. Proc., vol. 49, no. 8, pp. 1855-1863, 2017.

[20] F. D. W. Miller and L. J. Abu-Raddad, "Evidence of intense ongoing endemic transmission of hepatitis C virus in Egypt," Proc. Natl. Acad. Sci. U. S. A., vol. 107, no. 33, pp. 14757-14762, 2010.

[21] C. Frank et al., "The role of parenteral antischistosomal therapy in the spread of hepatitis C virus in Egypt," Lancet, vol. 355, no. 9207, pp. 887-891, 2000.

[22] A. Paez Jimenez et al., "HCV iatrogenic and intrafamilial transmission in Greater Cairo, Egypt," Gut, vol. 59, no. 11, pp. 1554-1560, 2010.

[23] S. A. Ali, R. M. J. Donahue, H. Qureshi, and S. H. Vermund, "Hepatitis B and hepatitis C in Pakistan: prevalence and risk factors," Int. J. Infect. Dis., vol. 13, no. 1, pp. 9-19, 2009.

[24] J. Guerra, M. Garenne, M. K. Mohamed, and A. Fontanet, "HCV burden of infection in Egypt: Results from a nationwide survey," J. Viral Hepat., vol. 19, no. 8, pp. 560-567, 2012.

[25] J. C. Eze, N. S. Ibeziako, A. N. Ikefuna, I. C. Nwokoye, N. D. Uleanya, and G. C. Ilechukwu., "Prevalence and risk factors for hepatitis $\mathrm{c}$ and human immunodeficiency virus coinfection among children in Enugu Nigeria," African J. Infect. Dis., vol. 8, no. 1, pp. 5-8, 2014.

[26] K. Mohd Hanafiah, J. Groeger, A. D. Flaxman, and S. T. Wiersma, "Global epidemiology of hepatitis C virus infection: New estimates of age-specific antibody to HCV seroprevalence," Hepatology, vol. 57, no. 4, pp. 1333-1342, 2013.

[27] M. Dahiya, T. Hussaini, and E. M. Yoshida, "The revolutionary changes in hepatitis C treatment:," no. march, pp. 72-77, 2019.

[28] V. Populations, "The management of chronic hepatitis C: 2018 guideline update from the Canadian Association for the Study of the Liver," vol. 190, no. 22, pp. 677-687, 2018. 
[29] S. Lanini, P. J. Easterbrook, A. Zumla, and G. Ippolito, "Hepatitis C: global epidemiology and strategies for control," Clin. Microbiol. Infect., vol. 22, no. 10, pp. 833-838, 2016.

[30] J. M. Pawlotsky, "Use and interpretation of virological tests for hepatitis C," Hepatology, vol. 36, no. 5 I, pp. 65-73, 2002.

[31] J. M. Pawlotsky, M. Bouvier-Alias, C. Hezode, F. Darthuy, J. Remire, and D. Dhumeaux, "Standardization of hepatitis C virus RNA quantification," Hepatology, vol. 32, no. 3, pp. 654-659, 2000.

[32] S. D. Holmberg, P. R. Spradling, A. C. Moorman, M. M. Denniston, S. Branch, and T. N. Health, "HHS Public Access," vol. 368, no. 20, pp. 1859-1861, 2017.

[33] S. Andrew and R. T. Chung, "Hepatitis C treatment: an incipient therapeutic revolution," Trends Mol. Med., pp. 1-7, 2014.

[34] H. S. Te, G. Randall, and D. M. Jensen, "Treatment of Chronic Hepatitis C," vol. 3, no. 3, pp. 218-225, 2007.

[35] N. A. Cook and S. D. Taylor-robinson, "Hepatitis C treatment: where are we now ?," pp. 39-52, 2017.

[36] B. Globke et al., "Treatment of hepatitis C virus recurrence after transplantation with sofosbuvir/ledipasvir: the role of ribavirin," 2016.

[37] J. Medina, L. Garc, J. A. Moreno-monteagudo, and R. Moreno-otero, "Combined antiviral options for the treatment of chronic hepatitis C," vol. 60, pp. 135-143, 2003.

[38] A. Manuscript and I. A. Response, "NIH Public Access," vol. 33, no. 7, pp. 999-1007, 2014.

[39] M. Charlton et al., "Ledipasvir and Sofosbuvir Plus Ribavirin for Treatment of HCV Infection in Patients with Advanced Liver Disease," Gastroenterology, 2015.

[40] M. S. Rezaee-zavareh and K. Hesamizadeh, "Combination of Ledipasvir and Sofosbuvir for Treatment of Hepatitis C Virus Genotype 1 Infection: Systematic Review and Meta-Analysis," Ann. Hepatol., vol. 16, no. 2, pp. 188-197, 2019.

[41] P. With et al., "PANCREAS , BILIARY TRACT , AND LIVER Without Cirrhosis," Clin. Gastroenterol. Hepatol., vol. 16, no. 3, pp. 417-426, 2018.

[42] M. P. Curry et al., "Sofosbuvir and Ribavirin Prevent Recurrence of HCV Infection after Liver Transplantation: An Open-Label Study," Gastroenterology, 2014.

[43] M. Charlton et al., "Sofosbuvir and Ribavirin for Treatment of Compensated Recurrent Hepatitis C Virus Infection After Liver Transplantation," Gastroenterology, vol. 148, no. 1, pp. 108-117, 2015. [44] P. Martin and D. M. Jensen, "Ribavirin in the treatment of chronic hepatitis C," vol. 23, no. 33, pp. 844-855, 2008. 
[45] E. F. Duffell, D. Hedrich, O. Mardh, and A. Mozalevskis, "Towards elimination of hepatitis B and $C$ in European Union and European Economic Area countries: monitoring the World Health Organization 's global health sector strategy core indicators and scaling up key interventions," pp. 1$5,2021$.

[46] V. E. Cells et al., "Ribavirin Treatment Up-Regulates Antiviral Gene Expression via the Interferon-Stimulated Response Element in Respiratory Syncytial," vol. 77, no. 10, pp. 5933-5947, 2003.

[47] N. M. Dixit, J. E. Layden-almer, T. J. Layden, and A. S. Perelson, "Modelling how ribavirin improves interferon response rates in hepatitis C virus infection," vol. 432, no. December, pp. 14-16, 2004.

[48] J. Molina et al., "Sofosbuvir plus ribavirin for treatment of hepatitis $C$ virus in patients co-infected with HIV ( PHOTON-2 ): a multicentre, open-label, non-randomised, phase 3 study," vol. 6736, no. 14, pp. 1-9, 2015.

[49] E. J. Gane et al., "Efficacy of Nucleotide Polymerase Inhibitor Sofosbuvir Plus the NS5A Inhibitor Ledipasvir or the NS5B Non-Nucleoside Inhibitor GS-9669 Against HCV Genotype 1 Infection," Gastroenterology, vol. 146, no. 3, pp. 736-743.e1, 2014.

[50] D. Andronescu, S. Diaconu, N. Tiuca, P. Rm, and A. Ci, "Hepatitis C Treatment \& Management," vol. 7, no. 1, pp. 31-36, 2014. 